\title{
Defining Competence in the Evolving Field of Pediatric Hospital Medicine
}

\author{
Meghan L Fanta, MD ${ }^{1,2 \star}$, Jacqueline M Walker, MD, MHPE ${ }^{3}$, Karen E Jerardi, MD, MEd ${ }^{1,2}$
}

'Division of Hospital Medicine, Cincinnati Children's Hospital Medical Center, Cincinnati, Ohio; ${ }^{2}$ University of Cincinanati College of Medicine, Cincinnati, Ohio; ${ }^{3}$ Division of Hospital Medicine, Children's Mercy Kansas City, Kansas City, Missouri.

ore competencies are intended to provide defined expectations in a field of medicine. The newly published Pediatric Hospital Medicine (PHM) Core Competencies: 2020 Revision are an update of the original 2010 competencies $^{1}$ with added and restructured content based on relevance to current practice. ${ }^{2,3}$ This is timely given the 2017 update to the Society of Hospital Medicine (SHM) core competencies $^{4}$ and recent designation of PHM as a boarded subspecialty by the American Board of Pediatrics (ABP). The competencies help define the knowledge, skills, and attitudes of a pediatric hospital medicine specialist and inform curriculum development to achieve the determined expectations.

In this update to the PHM core competencies, key adjustments were made to the editorial process. Importantly, a community hospitalist was added to the editorial team; this change better reflects the proportion of care provided to hospitalized children at community sites nationwide. ${ }^{5}$ Content updates were considered using a two-pronged needs assessment: (1) review of recent PHM conference, textbook, and handbook content and (2) survey of the SHM, Academic Pediatric Association, and American Academy of Pediatrics stakeholder groups. These processes led to the addition of 12 chapters, the major revision of 7 chapters, and the addition of content to 29 of the original chapters.

The increased focus on mental health in the sections "Common Clinical Diagnoses and Conditions" and "Specialized Services" is a necessary update. Chapters on neonatal abstinence syndrome (NAS), substance abuse, and altered mental status were added to the "Common Clinical Diagnoses and Conditions" section. The increasing incidence of NAS has been well described, and the field of PHM has been instrumental in improving care for these patients. ${ }^{6}$ Children hospitalized with mental health diagnoses constitute a substantial portion of pediatric inpatient admissions, ${ }^{7}$ and we anticipate that it will be a continued area of need in PHM. Therefore, the addition of chapters on acute and chronic behavioral and psychiatric conditions in the "Specialized Services" section is noteworthy. In contrast, with the added chapters on constipation and gastrointestinal and digestive disorders, the gastrointestinal disorders may be disproportionately represented in the updated competencies and may be an area to streamline in future iterations.

\footnotetext{
*Corresponding Author: Meghan Fanta, MD; Email: meghan.fanta@cchmc. org; Telephone: 513-803-4829; Twitter: @meghanfanta.
}

Received: February 28, 2020; Accepted: February 28, 2020

๑ 2020 Society of Hospital Medicine DOI 10.12788/jhm.3404
Recognition of changing procedural needs in the inpatient pediatric setting, particularly with the growing population of children with medical complexity, resulted in removal of suprapubic bladder taps and addition of vesicostomy care to the "Core Skills" section. In future updates, it will be important to continue to remove practices that are no longer relevant or widespread and include advances in procedural skills applicable to PHM such as point-of-care ultrasound. ${ }^{8}$

The "Healthcare Systems" section highlights additional skills ranging from quality improvement and research to familycentered care that PHM physicians bring to healthcare institutions. According to a recent survey of early-career hospitalists, skills in these areas are often not adequately developed during residency training. ${ }^{9}$ Therefore, the competencies outlined in this section are a key part of proposed PHM fellowship curricula ${ }^{10}$ and should be recognized as potential development opportunities for junior faculty in the field. This section also highlights the increasing medical complexity of patients and evolving role of PHM expertise in comanagement and consultation to improve quality and safety of care. Appreciating the unique needs of underserved communities is another important addition in the new chapter on family-centered care.

Looking ahead to future updates, we appreciate that the editors commented on diversity in both editorship and authorship. In line with the recent call for improved representation of women and racial and ethnic minorities in academic medicine by the Journal of Hospital Medicine, ${ }^{11}$ future core competency publications should broadly consider diversity in editors, authors, and reviewers and more explicitly address methods for increasing diversity. We also anticipate that technological advances, such as telemedicine and remote patient monitoring, will be at the forefront in subsequent updates, which will allow higher levels of care to be provided outside of the traditional hospital structure. With the recent inauguration of the ABP PHM certification exam and the first cycle of Accreditation Council for Graduate Medical Education accreditation for PHM fellowships, these updated competencies are timely and relevant. The authors' ongoing efforts are crucial for our young and evolving field as we strive to improve the health of all hospitalized children.

Disclosures: The authors have nothing to disclose.

\section{References}

1. Stucky ER, Ottolini MC, Maniscalco J. Pediatric Hospital Medicine Core Competencies: development and methodology. J Hosp Med. 2010;5(6): 339-343. https://doi.org/10.1002/jhm.843 
2. Gage S, Maniscalco J, Fisher E, Teferi S, et al. The Pediatric Hospital Medicine Core Competencies: 2020 Revision; a framework for curriculum development by the Society of Hospital Medicine with acknowledgment to pediatric hospitalists from the Academic Pediatric Association and the American Academy of Pediatrics. J Hosp Med. 2020;15(S1):1-155

3. Maniscalco J, Gage S, Teferi S, Stucky Fisher E. The Pediatric Hospital Medicine Core Competencies 2020 Revision: introduction and methodology. J Hosp Med. 2020;15(7):389-394. https://doi.org/10.12788/jhm.3391

4. Nichani S, Crocker J, Fitterman N, Lukela M. Updating the Core Competencies in hospital medicine--2017 revision: introduction and methodology. J Hosp Med. 2017;12(4):283-287. https://doi.org/10.12788/jhm.2715

5. Leyenaar JK, Ralston SL, Shieh M-S, Pekow PS, Mangione-Smith R, Lindenauer PK. Epidemiology of pediatric hospitalizations at general hospitals and freestanding children's hospitals in the United States: pediatric hospitalization epidemiology. J Hosp Med. 2016;11(11):743-749. https://doi.org/10.1002/jhm.2624

6. Holmes AV, Atwood EC, Whalen B, et al. Rooming-in to treat neonatal abstinence syndrome: improved family-centered care at lower cost. Pediatrics. 2016;137(6):e20152929. https://doi.org/10.1542/peds.2015-2929

7. Bardach NS, Coker TR, Zima BT, et al. Common and costly hospitalizations for pediatric mental health disorders. Pediatrics. 2014;133(4):602-609. https:// doi.org/10.1542/peds.2013-3165

8. Conlon TW, Nishisaki A, Singh Y, et al. Moving beyond the stethoscope: diagnostic point-of-care ultrasound in pediatric practice. Pediatrics. 2019;144(4):e20191402. https://doi.org/10.1542/peds.2019-1402

9. Librizzi J, Winer JC, Banach L, Davis A. Perceived core competency achievements of fellowship and non-fellowship-trained early career pediatric hospitalists: early career pediatric hospitalists. J Hosp Med. 2015;10(6):373-379. https://doi.org/10.1002/jhm.2337

10. Jerardi KE, Fisher E, Rassbach C, et al. Development of a curricular framework for Pediatric Hospital Medicine fellowships. Pediatrics. 2017;140(1):e20170698. https://doi.org/10.1542/peds.2017-0698

11. Shah SS, Shaughnessy EE, Spector ND. Leading by example: how medical journals can improve representation in academic medicine. J Hosp Med. 2019;14(7):393. https://doi.org/10.12788/jhm.3247 